\title{
LISSOCLINUM ARGYLLENSE N.SP., A NEW ASCIDIAN FROM SCOTLAND
}

\author{
By R. H. Millar \\ The Marine Station, Millport
}

(Text-fig. I)

In the summer of I949 a compound ascidian was collected from the shore of Seil Island, Argyll. This proved to be a new species of the family Didemnidae. It is proposed to name it Lissoclinum argyllense, the specific name indicating the area in which it was first found. No species of Lissoclinum has hitherto been included in the British fauna.

Occurrence. Colonies have been found round the shores of Seil Island, Argyll, and on the shore at Salen in the Isle of Mull, Argyll. All colonies were on the under sides of stones in the intertidal zone. They were not common, except locally, where several colonies sometimes occurred within a few yards of each other.

The colony (Fig. IA) is usually pure white but is sometimes tinged with pink or buff. It forms encrusting sheets up to $50 \mathrm{~mm}$. in diameter and about $2 \mathrm{~mm}$. thick. The colony is rather flaccid and the upper layer of the test can be easily torn away from the lower layer. The oral openings (Fig. I A, Or.op.), which are scattered evenly over the surface, are round and more conspicuous than those on the colony of Didemnum maculosum (Edwards), with which the present species might be confused. Cloacal openings (Fig. I A, Cl.op.) are also conspicuous and are round or elliptical. The cloacal cavities are very greatly developed within the colony and leave little more than a thin upper and lower layer of test between which the zooids are stretched. In these upper and lower layers spicules are densely packed, giving the colony its white appearance. The zooids are arranged in the colony in irregular rows.

The spicules (Fig. IB) are of a very characteristic shape, which at once distinguishes them from those of Didemnum. In optical section they show four to six rays, which are not conical and pointed as in D. maculosum, but have instead a broad end with two or three rounded prominences. The spicules are $0.03-0.05 \mathrm{~mm}$. in diameter. They somewhat resemble the spicules of $D$. perforatum (Giard).

The zooid (Fig. IC) is about $\mathrm{I} \cdot 8 \mathrm{~mm}$. long. The oral siphon has six short pointed equal lobes. There is no atrial siphon. The atrial opening, which is without a languet, is very large and extends round the thorax to near the endostyle, so exposing nearly the whole branchial sac. The tentacles number 


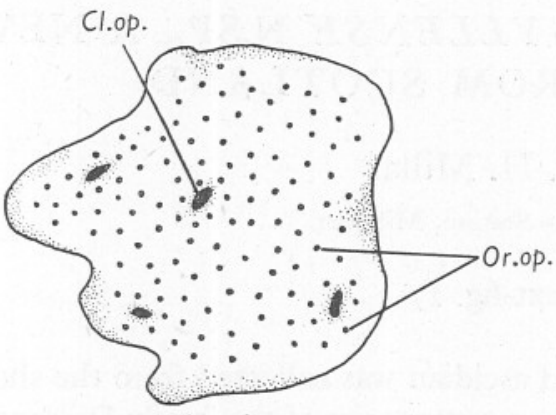

A

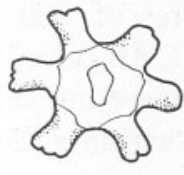

B

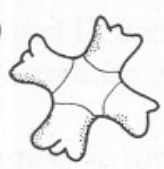

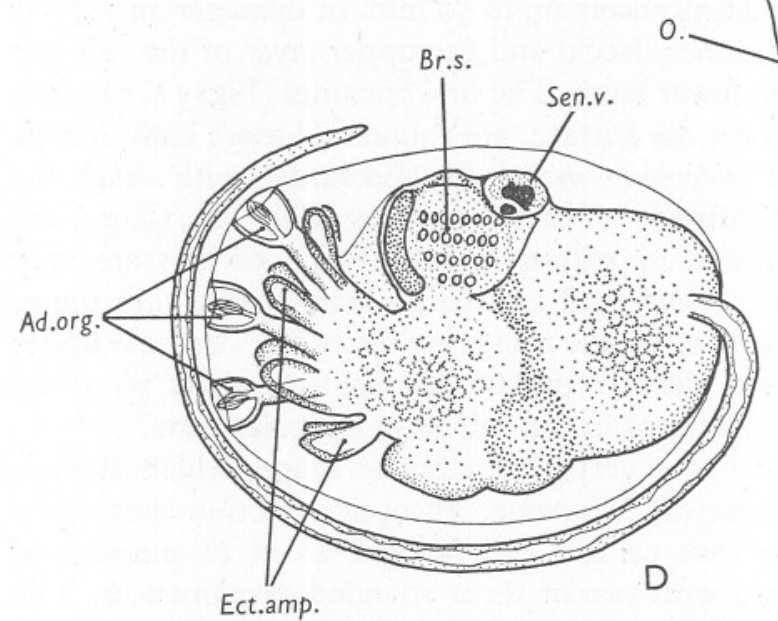

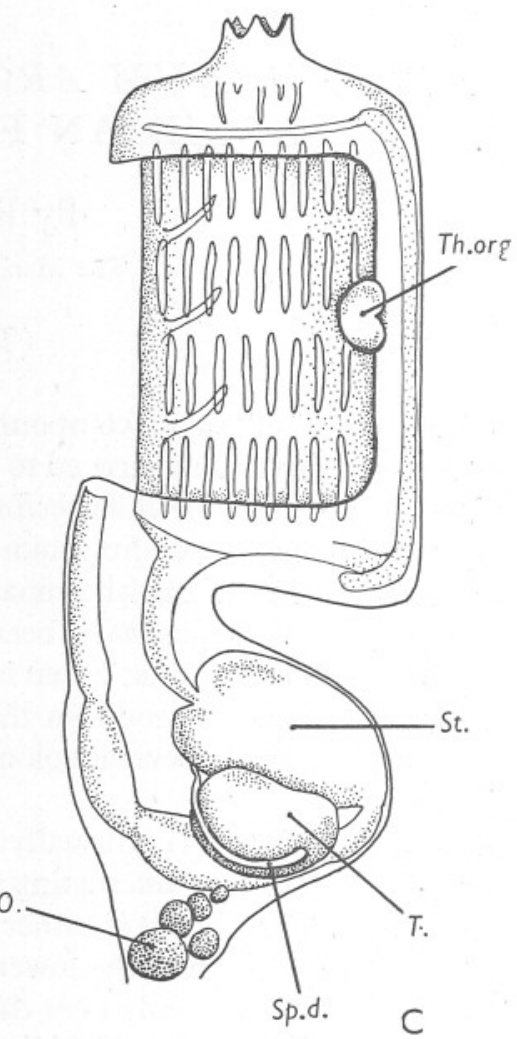

$$
\text { Ect.amp. }
$$

Fig. I. Lissoclinum argyllense n.sp. A, colony; B, spicules; C, zooid, seen from the right; D, larva, seen from the left. Ad.org., anterior adhesive organs; Br.s., rudiment of the branchial sac; Cl.op., cloacal opening; Ect.amp., ectodermal ampullae; O., ovary; Or.op., oral openings; Sen.v., sensory vesicle; Sp.d., sperm duct; St., stomach; T., testis; Th.org., lateral thoracic organ. 
up to 24 and alternate in size. There are four rows of stigmata in the branchial sac, each row having eight or nine stigmata. The three dorsal languets of the pharynx are quite large. A lateral thoracic organ (Fig. IC, Th.org.) is present on each side of the body, on the ventral margin of the atrial opening, between the second and third rows of stigmata. Beside each thoracic organ is a large mass of spicules. The abdomen is shorter than the thorax and contains the slightly curved oesophagus, the ovoid smooth-walled stomach (Fig. I C, St.), the intestine divided into three long chambers, and the rectum extending to the level of the fourth row of stigmata. In the intestinal loop is a single large round testis (Fig. I C, T.). The sperm duct (Fig. I C, Sp.d.) is not spirally coiled but passes round in a half circle to the lower side of the testis, where its origin is marked by a slight thickening. The ovary (Fig. I C, O.) has a string of ova extending from the lower part of the intestinal loop down into the common test below the abdomen. Apparently the ova in development pass down into the lower layer of common test, where the larvae are found. Asexual reproduction is by pyloric budding as in other didemnids.

Larvae (Fig. I D) were found in colonies collected in August and November, but may have been present in other months when no colonies were examined. The larvae were embedded in the lower layer of the common test. In general organization the larva of Lissoclinum argyllense resembles the larva of other didemnids. It measures $0.6 \mathrm{~mm}$. from the end of the adhesive organs to the base of the tail. The sensory vesicle (Fig. I D, Sen.v.) has a small ovoid static organ on the floor and a larger ocellus on the posterodorsal wall. The rudiment of the branchial sac (Fig. I D, Br.s.) has four horizontal rows of stigmata and a vertical endostyle. At the anterior end of the larva there are eight ectodermal ampullae (Fig. I D, Ect.amp.) and a vertical row of three adhesive organs (Fig. I D, Ad.org.).

Systematic position. This new species shows the common characteristics of the family Didemnidae, into which it falls naturally. The genera of this family are divisible into two groups identified thus:

(a) The proximal part of the sperm duct always spirally coiled; the common cloacal cavities generally not greatly developed.

(b) The proximal part of the sperm duct never spirally coiled; the common cloacal cavities often greatly developed.

The second group contains Diplosoma (Macdonald), Lissoclinum (Verrill), and Echinoclinum (Van Name), and to it the new species belongs. It is excluded from Diplosoma by the possession of spicules, and from Echinoclinum by the shape of the spicules. It agrees closely with Lissoclinum in all features examined except in its undivided testis. All species of Lissoclinum hitherto described have two or more testis follicles. Thus L. aureum Verrill has five to ten follicles, most species have two follicles, and Echinoclinum, which Van Name (I945) is inclined to regard as a subgenus of Lissoclinum, has the testis only partially divided into two by a deep groove. L. argyllense, with its undivided 
R. H. MILLAR

testis, appears to stand at one end of this series. By including the new species in Lissoclinum we expand the definition of that genus to include forms with an undivided testis.

\section{REFERENCE}

VAn Name, W. G., I945. The North and South American ascidians. Bull. Amer. Mus. Nat. Hist., Vol. 84, 476 pp. 